\title{
MASTITIS DETECTION FROM MILK MID-INFRARED (MIR) SPECTROSCOPY IN DAIRY COWS
}

\author{
Lisa Rienesl1, Negar Khayatzadeh ${ }^{1}$, Astrid Köck², Laura Dale ${ }^{3}$, Andreas Werner ${ }^{3}$, \\ Clément Grelet ${ }^{4}$, Nicolas Gengler ${ }^{5}$, Franz-Josef Auer ${ }^{6}$, Christa Egger-Danner ${ }^{2}$, \\ Xavier Massart ${ }^{7}$, Johann Sölkner ${ }^{1}$ \\ ${ }^{1}$ University of Natural Resources and Life Sciences, Vienna (BOKU), Division of Livestock Sciences, Department of \\ Sustainable Agricultural Systems, Gregor-Mendel-Strasse 33, A-1180 Vienna, Austria \\ 2 ZuchtData EDV-Dienstleistungen GmbH, Dresdner Straße 89/19, A-1200 Vienna, Austria \\ ${ }^{3}$ Landesverband Baden-Württemberg für Leistungs- und Qualitätsprüfungen in der Tierzucht e.V. (LKV), \\ Heinrich-Baumann Straße 1-3, 70190 Stuttgart, Germany \\ ${ }^{4}$ Centre Wallon de Recherches Agronomiques (CRA-W), Chaussée de Namur 24, B-5030 Gembloux, Belgium \\ ${ }^{5}$ Université de Liège (ULg), Gembloux Agro-Bio Tech, Passage des Déportés 8, B-5030 Gembloux, Belgium \\ ${ }^{6}$ LKV Austria Gemeinnützige GmbH, Dresdner Straße 89/19, A-1200 Wien, Austria \\ ${ }^{7}$ European Milk Recording (EMR), Rue des Champs Elysées 4, 5590 Ciney, Belgium
}

To link to this article: https://doi.org/10.11118/actaun201967051221

Received: 22. 7. 2019, Accepted: 25. 9. 2019

To cite this article: RIENESL LISA, KHAYATZADEH NEGAR, KÖCK ASTRID, DALE LAURA, WERNER ANDREAS, GRELET CLÉMENT, GENGLER NICOLAS, AUER FRANZ-JOSEF, EGGER-DANNER CHRISTA, MASSART XAVIER, SÖLKNER JOHANN. 2019. Mastitis Detection from Milk Mid-Infrared (MIR) Spectroscopy in Dairy Cows. Acta Universitatis Agriculturae et Silviculturae Mendelianae Brunensis, 67(5): 1221-1226.

\begin{abstract}
Mid-infrared (MIR) spectroscopy is the method of choice for the standard milk recording system, to determine milk components including fat, protein, lactose and urea. Since milk composition is related to health and metabolic status of a cow, MIR spectra could be potentially used for disease detection. In dairy production, mastitis is one of the most prevalent diseases. The aim of this study was to develop a calibration equation to predict mastitis events from routinely recorded MIR spectra data. A further aim was to evaluate the use of test day somatic cell score (SCS) as covariate on the accuracy of the prediction model. The data for this study is from the Austrian milk recording system and its health monitoring system (GMON). Test day data including MIR spectra data was merged with diagnosis data of Fleckvieh, Brown Swiss and Holstein Friesian cows. As prediction variables, MIR absorbance data after first derivatives and selection of wavenumbers, corrected for days in milk, were used. The data set contained roughly 600,000 records and was split into calibration and validation sets by farm. Calibration sets were made to be balanced (as many healthy as mastitis cases), while the validation set was kept large and realistic. Prediction was done with Partial Least Squares Discriminant Analysis, key indicators of model fit were sensitivity and specificity. Results were extracted for association between spectra and diagnosis with different time windows (days between diagnosis and test days) in validation. The comparison of different sets of predictor variables (MIR, SCS, MIR + SCS) showed an advantage in prediction for MIR + SCS. For this prediction model, specificity was 0.79 and sensitivity was 0.68 in time window -7 to +7 days (calibration and validation). Corresponding values for MIR were 0.71 and 0.61 , for SCS they were 0.81 and 0.62 . In general, prediction of mastitis performed better with a shorter distance between test day and mastitis event, yet even for time windows of -21 to +21 days, prediction accuracies were still reasonable, with sensitivities ranging from 0.50 to 0.57 and specificities remaining unchanged (0.71 to 0.85 ).
\end{abstract}


Additional research to further improve prediction equation, and studies on genetic correlations among clinical mastitis, SCS and MIR predicted mastitis are planned.

Keywords: MIR spectroscopy, dairy cow, milk, mastitis, somatic cell count, PLS

\section{INTRODUCTION}

This study is part of the project D4dairy, the overall goal of which is to provide digital support to dairy management by a data-driven, networked information system, exploiting the potential of advanced technologies and data analysis to further improve animal health, nutrition, animal welfare and product quality (D4Dairy Consortium, 2019). A subarea of D4dairy is disease detection using Midinfrared (MIR) milk spectral data. MIR spectroscopy is a method of choice for standard milk recording systems to measure milk contents including fat, protein, lactose and urea. Besides, MIR spectra data could be used to predict other milk components (De Marchi et al., 2014). Because it is well known that the composition of milk is related to the health and metabolic status of the cow, its changes can be potential indicators (e. g. Hamann and Krömker, 1997). In recent years, MIR spectra data have been used to predict different variables of interest, such as fatty acid composition of milk (Soyeurt et al., 2006; 2011), methane emissions (Vanlierde et al., 2015), feed intake (Wallén et al., 2018), energy intake and efficiency (McParland et al., 2014) or ration composition (Klaffenböck et al., 2016). There are several studies on health traits and diseases, e.g. subclinical ketosis (De Roos et al., 2007) and clinical ketosis (Belay et al., 2016), mastitis (Soyeurt et al., 2011; Dale and Werner, 2017) and lameness (Mineur et al., 2017). The focus of this study was on detection of mastitis, which is one of the most prevalent diseases in dairy production. Mastitis diseases cause economic harm due to milk losses, costs for veterinarians, earlier culling and not least, affects the animal welfare (Halasa et al., 2007; Heikkilä et al., 2012; Guimarães et al., 2017). MIR spectra analysis could be an extra tool, additionally to somatic cell count (SCC) and veterinarian diagnosis, for mastitis prediction, to further improve genetic evaluation of the trait 'Udder health', or to provide farmers with a management tool. The main aim of this study was to develop a calibration equation to predict mastitis events from routinely recorded MIR spectra data. We further aimed to evaluate the effect of different calibration settings and the use of somatic cell score (SCS) as covariate on the sensitivity and specificity of the prediction model.

\section{MATERIALS AND METHODS}

The data for this study was from the Austrian milk recording system and its health monitoring system (GMON), for the period of July 2014 to December 2018 and was provided by Zuchtdata $\mathrm{GmbH}$.
The test day milk data consisted of information on breed, herd, region, calving date, parity, days in milk, milk yield, somatic cell count (SCC), fat, protein and MIR spectra data for the respective test days. The GMON data included recorded mastitis diagnosis for acute and chronic mastitis, where both were used equally for the prediction model. All data (test day and GMON) used in this study were derived from validated farms with complete data recording. Merging of the data sets and primary data preparation were done in SAS (SAS Institute Inc., 2017). Mastitis diagnoses were linked with 'adjacent' milk recording test days. Test day records in the range of 21 days before and 21 days after diagnosis were considered as mastitis cases. For the healthy group, only spectra from cows without mastitis diagnosis 21 days before and 30 days after test day were used. Test day records of Fleckvieh, Brown Swiss and Holstein Friesian cows between 3 and 305 days of lactation were included. Tab. I shows the number of records of final the data set.

I: Records of the final data set

\begin{tabular}{lc}
\hline Variables & Number of records \\
\hline Farms & 7,914 \\
Animals (Cows): & 69,028 \\
- Fleckvieh & 52,287 \\
- Brown Swiss & 7,260 \\
- Holstein Friesian & 9,481 \\
\hline Test day records & 635,588 \\
\hline healthy & 627,593 \\
mastitis: & 7,995 \\
- acute & 5,644 \\
- chronic & 2,351 \\
\hline
\end{tabular}

MIR spectra consist of 1,060 data points, which are the absorbance values of infrared light at different wavenumbers (925.66 $\mathrm{cm}^{-1}$ to $5010.16 \mathrm{~cm}^{-1}$ ). MIR spectra from different instruments and different periods were previously standardized into a common basis (Grelet et al., 2015). According to Grelet et al. (2016), selected parts of the spectra were used for the prediction model: 968.1 to $1,577.5 \mathrm{~cm}^{-1}$, $1,731.8$ to $1,762.6 \mathrm{~cm}^{-1}, 1,781.9$ to $1,808.9 \mathrm{~cm}^{-1}$, and $2,831.0$ to $2,966.0 \mathrm{~cm}^{-1}$. These spectra areas (212 data points) contain most of the information, whilst other areas are 'noisy', because of strong water absorbance or not repeatable among MIR 
instruments. Before selecting the specific areas, first derivative $(d x(n)=x(n)-x(n+4))$ of full spectra was taken.

Further data preparation was done in Rstudio (R Development Core Team, 2008). The 212 selected spectra variables were corrected for days in milk (DIM), according to Vanlierde et al. (2015): Each first derivative value of the selected spectra was multiplied by a constant (i.e., 1), a linear $(\sqrt{ } 3 \times x)$ and a quadratic $\left[\sqrt{5} / 4 \times\left(3 x^{2}-1\right)\right]$ modified Legendre polynomial (Gengler et al., 1999), where $\mathrm{x}=-1+2[(\mathrm{DIM}-3) /(305-3)]$. This modification resulted in 636 (212 constant, 212 linear, 212 quadratic) spectra variables, which were finally used for the prediction model. The somatic cell count (SCC) was logarithmically transformed to the somatic cell score (SCS), by applying the formula: SCS $=\log 2(S C C / 100,000)+3$ (Fürst et al., 2016).

The 635,588 records of the complete data set where randomly split by farm into half a calibration (train) and half a validation (test) data set. In this way, cows in the validation set were from different herds than those in the calibration set. In final calibration data sets, the numbers of healthy and mastitis cases were always balanced (1:1) by using random down sampling. Further, different settings were applied on the calibration set for testing various factors.

The first objective was to test the effect of SCC restrictions for mastitis diagnosis in calibration: Animals were considered as healthy, if Diagnosis $=0$ and SCC <= 100,000; animals were considered to have mastitis, if Diagnosis $=1$ and SCC $>=400,000$. Observations that did not fulfill these conditions were deleted. Another subset was created without SCC restrictions. This comparison was done for all model tests. The second aim was to compare different sets of predictor variables: MIR (636 DIM corrected spectral data points), SCS alone and MIR plus SCS as covariate. For all calibration subsets, the maximum days between diagnosis and test day were set to -7 to +7 days, according to Soyeurt et al. (2012). In validation, mastitis cases with maximum -21 to +21 days between diagnosis and test day were considered. In order to have a realistic validation data set, no further settings or restrictions were applied. The results of validation (Tab. III) are displayed for the overall time window of -21 to +21 days and additionally split for different shorter time windows. This was to demonstrate the difference in prediction of mastitis cases, if test day is before or after mastitis event and how accuracy of prediction changes with the distance of days between mastitis event and test day.

Prediction was done with Partial Least Squares Discriminant Analysis (PLS-DA), using the R package 'caret' (Kuhn, 2008). The indicators of model fit were sensitivity (mastitis cases correctly assigned as mastitis), specificity (healthy cases correctly assigned as healthy) and balanced accuracy (mean of sensitivity and specificity). The number of latent variables used in the prediction models was 50, based on preliminary tests. When just SCS was used as predictor variable, the number of latent variables was set to one.

We chose to run 20 replications per setting. Given a standard deviation of 0.017 for replicates, that allowed to detect significance at a p-value of 0.05 for differences of around 0.015. Sample size calculator (https://www.stat.ubc.ca/ rollin/stats/ssize/n2.html) was used.

\section{RESULTS}

For testing the effect of different predictor variables (MIR, SCS, MIR + SCS), the number of records was on average 2,340 (1,170 mastitis, 1,170 healthy) for the calibration sets without SCC limits, and 1,086 (543 mastitis, 543 healthy) for the calibration sets with SCC limits. Thus, applying SCC limits reduced the size of the calibration set roughly to half.

Tab. II displays the results of PLS-DA procedure in calibration set. For the different predictor variables (MIR, SCS, MIR + SCS), sensitivity, specificity and balanced accuracy was higher in the calibration set with SCC limits. For SCS and MIR + SCS all indicators were 1, for MIR alone sensitivity was 0.84 and specificity 0.89. In the calibration set without SCC limits, sensitivities and specificities were lower for all types of models.

Tab. III shows the results of model testing for the validation set. All the results were for the full validation set $(-21$ to +21 days). Splitting it into different shorter time windows changed the number of mastitis cases, but not the number of healthy cases. Therefore, specificities of different time windows did not differ from specificity of the overall time window. Differences in balanced accuracy resulted from changing sensitivity.

II: Results in calibration (train) for different predictor variables (MIR, SCS or MIR + SCS); with and without SCC limits in train

\begin{tabular}{lcccccc}
\hline \multirow{2}{*}{$\begin{array}{c}\text { Predictor } \\
\text { variable }\end{array}$} & \multicolumn{3}{c}{ no SCC limits in train } & \multicolumn{3}{c}{ SCC limits in train } \\
\cline { 2 - 7 } MIR & sens. & spec. & bal.acc. & sens. & spec. & bal.acc. \\
\hline SCS & 0.680 & 0.770 & 0.725 & 0.843 & 0.886 & 0.864 \\
MIR + SCS & 0.617 & 0.849 & 0.733 & 1.000 & 1.000 & 1.000 \\
\hline
\end{tabular}

sens. = sensitivity; spec. = specificity; bal.acc. = balanced accuracy 
Applying SCC limits in calibration did not lead to a higher balanced accuracy in validation, compared to prediction equations derived from calibration data sets without SCC limits (Tab. II). For all models, specificity was higher with SCC limits, but sensitivity was lower. The differences in sensitivity (all time windows) and specificity were significant for MIR and MIR + SCS. Without SCC limits sensitivity and specificity were more balanced and balanced accuracy was slightly higher for all variants, except, SCS (-21 to +21 days), SCS (-21 to -15 days), SCS (-7 to +7 days) and MIR + SCS (-14 to -8 days).

Comparing the different predictor variables in the models without SCC limits in calibration gave the following results: Overall sensitivity was significantly higher for MIR, but overall specificity was significantly higher for SCS. For the individual time windows (except -14 to -8 days), the highest balanced accuracies were found for MIR + SCS. For the comparison of predictor variables with SCC limits in calibration, specificity was highest for MIR + SCS (0.88) and lowest for MIR alone (0.76) for the -21 to +21 days time window. For the overall validation set, the highest sensitivity (0.49) was also reached by SCS alone. With regard to the individual time windows, sensitivity of SCS was the highest (significantly) for -7 to +7 days, -14 to -8 days and
-21 to -15 days, but for +15 to +21 days and +8 to +14 days it was highest (significantly) for MIR alone.

\section{DISCUSSION}

Considering the results for calibration data sets, the sensitivity and specificity of 1.00 for predictor variables SCS and MIR + SCS, and also high values for MIR alone, when using SCC limits, are due to overfitting of the model. Applying the particular model on the realistic validation set did not show an advantage of using SCC limits in calibration. It resulted in a higher imbalance of sensitivity and specificity and a lower balanced accuracy, compared to the model without SCC limits in train. This imbalance of sensitivity and specificity was also found in the study of Soyeurt et al. (2012), where MIR predicted lactoferrin was used as an indicator for mastitis.

According to the results, the predictor model without applying SCC limits in calibration, is more adequate. Therefore, the discussion of further effects focusses on that model. Tab. III clearly demonstrates that the prediction of mastitis cases works better with a shorter distance between diagnosis and test day in the validation dataset. The time window of -7 to +7 days in validation was also applied in the study of Soyeurt et al. (2012). When

III: The effect of different predictor variables (MIR, SCS or MIR + SCS) and SCC limits in calibration (train), results in validation (test) extracted for different time windows

\begin{tabular}{|c|c|c|c|c|c|c|c|}
\hline \multirow{2}{*}{ Predictor variables } & \multicolumn{3}{|c|}{ no SCC limits in train } & \multicolumn{3}{|c|}{ SCC limits in train } & \multirow{2}{*}{ windows test } \\
\hline & sens. & spec. & bal.acc. & sens. & spec. & bal.acc. & \\
\hline MIR & 0.534 & 0.708 & 0.621 & 0.457 & 0.755 & 0.606 & \multirow{3}{*}{-21 to +21 (overall) } \\
\hline SCS & 0.501 & 0.849 & 0.675 & 0.490 & 0.862 & 0.676 & \\
\hline MIR + SCS & 0.574 & 0.791 & 0.682 & 0.473 & 0.878 & 0.675 & \\
\hline MIR & 0.458 & 0.708 & 0.583 & 0.368 & 0.755 & 0.561 & \multirow{3}{*}{-21 to -15} \\
\hline SCS & 0.401 & 0.849 & 0.625 & 0.394 & 0.862 & 0.628 & \\
\hline $\mathrm{MIR}+\mathrm{SCS}$ & 0.474 & 0.791 & 0.633 & 0.373 & 0.878 & 0.626 & \\
\hline MIR & 0.484 & 0.708 & 0.596 & 0.412 & 0.755 & 0.584 & \multirow{3}{*}{-14 to -8} \\
\hline SCS & 0.513 & 0.849 & 0.681 & 0.499 & 0.862 & 0.681 & \\
\hline $\mathrm{MIR}+\mathrm{SCS}$ & 0.555 & 0.791 & 0.673 & 0.477 & 0.878 & 0.678 & \\
\hline MIR & 0.605 & 0.708 & 0.657 & 0.540 & 0.755 & 0.647 & \multirow{3}{*}{-7 to +7} \\
\hline SCS & 0.615 & 0.849 & 0.732 & 0.604 & 0.862 & 0.733 & \\
\hline $\mathrm{MIR}+\mathrm{SCS}$ & 0.678 & 0.791 & 0.735 & 0.586 & 0.878 & 0.732 & \\
\hline MIR & 0.560 & 0.708 & 0.634 & 0.478 & 0.755 & 0.617 & \multirow{3}{*}{+8 to +14} \\
\hline SCS & 0.466 & 0.849 & 0.658 & 0.447 & 0.862 & 0.655 & \\
\hline $\mathrm{MIR}+\mathrm{SCS}$ & 0.558 & 0.791 & 0.675 & 0.441 & 0.878 & 0.659 & \\
\hline MIR & 0.479 & 0.708 & 0.594 & 0.394 & 0.755 & 0.574 & \multirow{3}{*}{+15 to +21 } \\
\hline SCS & 0.374 & 0.849 & 0.612 & 0.361 & 0.862 & 0.612 & \\
\hline MIR + SCS & 0.475 & 0.791 & 0.633 & 0.347 & 0.878 & 0.612 & \\
\hline
\end{tabular}

sens. = sensitivity; spec. = specificity; bal.acc. $=$ balanced accuracy 
comparing the time windows with larger distance between diagnosis and test day, predictions with MIR + SCS were very similar for test days before and after the occurrence of mastitis events. Yet, considering SCS and MIR as predictors separately, results seem to indicate that MIR predicted mastitis better, when test days were after mastitis diagnosis, while SCS predicted mastitis events better, when test days were before diagnosis. Prediction equations combining SCS and MIR were overall best.

In general, the results presented here were hard to compare with a few other studies on MIR predicted mastitis, such as Soyeurt et al. (2012) and Dale and Werner (2017), because types of validation were very different.

\section{CONCLUSION}

This study explored the potential of milk MIR spectral data for prediction of mastitis cases. We investigated the utility of combining information of MIR and SCS, which were both available for every test day record. Results indicate that mastitis diagnoses may be predicted reasonably accurate, with balanced accuracies of 0.62 to 0.68 for time windows of $+/-21$ days between mastitis diagnosis and test day and up to 0.74 for shorter time windows. The information is potentially valuable for improved genetic evaluation of the trait 'Udder health', which is currently an index of SCS and clinical mastitis. Future studies on genetic correlations of clinical mastitis, SCS and MIR predicted mastitis will provide guidance in this direction.

Additional studies are planned to further improve the prediction model, by including the effects of milk yield, lactose, breed and parity.

\section{Acknowledgements}

This work was conducted within the COMET-Project D4Dairy (Digitalisation, Data integration, Detection and Decision support in Dairying). That is supported by BMVIT, BMDW and the provinces of Lower Austria and Vienna in the framework of COMET-Competence Centers of Excellent Technologies. The COMET program is handled by the FFG.

\section{REFERENCES}

BELAY, T. K., SVENDSEN, M., KOWALSKI Z. M. and ÅNØY, T. 2017. Genetic parameters of blood $\beta$-hydroxybutyrate predicted from milk infrared spectra and clinical ketosis, and their associations with milk production traits in Norwegian Red cows. Journal of Dairy Science, 100(8): 6298-6311.

DALE, L. and WERNER, A. 2017. "MastiMIR" - A warning system for mastitis based on MIR spectra [in German: "MastiMIR” - Ein Mastitis-Frühwarnsystem basierend auf MIR-Spektren]. In: Vortragstagung der DGfZ und GfT: Aus der Arbeit der Forschungsstätten für Tierwissenschaften. 20-21 September 2017, Stuttgart, Deutschland.

DE ROOS, A. P., VAN DEN BIJGAART, H. J., HØRLYK, J. and DE JONG, G. 2007. Screening for subclinical ketosis in dairy cattle by Fourier transform infrared spectrometry. Journal of Dairy Science, 90(4): 1761-1766.

D4DAIRY CONSORTIUM. 2019. D4Dairy. [Online]. Available at: https://d4dairy.com/de/\#projekt [Accessed: 2019, June 21].

FÜRST, C., DODENHOFF, J., EGGER-DANNER, C., EMMERLING, R., HAMANN, H., KROGMEIER, D. and SCHWARZENBACHER, H. 2019. Breeding value estimation in cattle-Basics, methods and interpretation [in German: Zuchtwertschätzung beim Rind - Grundlagen, Methoden und Interpretationen]. Vienna: ZuchtData EDV-Dienstleistungen GmbH.

GENGLER, N., TIJANI, A., WIGGANS, G. R. and MISZTAL, I. 1999. Estimation of (co)variance function coefficients for test day yield with an expectation-maximization restricted maximum likelihood algorithm. Journal of Dairy Science, 82(8): 1849.e1-1849.e23.

GRELET, C., FERnÁndeZ PIERNA, J. A., DARDENNE, P., BAETEN, V. and DEHARENG, F. 2015. Standardization of milk mid-infrared spectra from a European dairy network. Journal of Dairy Science, 98(4): 2150-2160.

GRELET, C., FERNÁNDEZ PIERNA, J. A., DARDENNE, P., SOYEURT, H., VANLIERDE, A., COLINET, F., GENGLER, N., BAETEN, V. and DEHARENG, F. 2016. Development of Fourier transform mid-infrared calibrations to predict acetone, $\beta$-hydroxybutyrate and citrate contents in bovine milk through a European dairy network. Journal of Dairy Science, 99(6): 4816-4825.

GUimarÃES, J. L., BRITO, M. A., LANGE, C. C., SilVA, M. R., RIBEIRO, J. B., MENDONÇA, L. C., MENDONÇA, J. F. M. and SOUZA, G. N. 2017. Estimate of the economic impact of mastitis: A case study in a Holstein dairy herd under tropical conditions. Preventive Veterinary Medicine, 142: 46-50. 
HAMANN, J. and KRÖMKER, V. 1997. Potential of specific milk composition variables for cow health management. Livestock Production Science, 48(3): 201-208.

HALASA, T., HUIJPS, K., ØSTERÅS, O. and HOGEVEEN, H. 2007. Economic effects of bovine mastitis and mastitis management: A review. Veterinary Quarterly, 29(1): 18-31.

HEIKKILÄ, A.-M., NOUSIAINEN, J. I. and PYÖRÄLÄ, S. 2012. Costs of clinical mastitis with special reference to premature culling. Journal of Dairy Science, 95(1): 139-150.

KLAFFENBÖCK, M., STEINWIDDER, A., FASCHING, C., TERLER, G., GRUBER, L., MÉSZÁROS, G. and SÖLKNER, J. 2016. The use of mid-infrared spectrometry to estimate the ration composition of lactating dairy cows. Journal of Diary Science, 100(7): 5411-5421.

KUHN, M. 2008. Building Predictive Models in R Using the caret Package. Journal of Statistical Software, 28(5): 1-26.

MCPARLAND, S., LEWIS, E., KENNEDY, E., MOORE, S. G., MC CARTHY, B., O’DONOVAN, M., BUTLER, S. T., PRYCE, J. E. and BERRY, D. P. 2014. Mid-infrared spectrometry of milk as a predictor of energy intake and efficiency in lactating dairy cows. Journal of Dairy Science, 97(9): 5863-5871.

MINEUR, A., KÖCK, A., GRELET, C., GENGLER, N., EGGER-DANNER, C. and SÖLKNER J. 2017. First Results in the Use of Milk Mid-infrared Spectra in the Detection of Lameness in Austrian Dairy Cows. Agriculturae Conspectus Scientificus, 82(2): 163-166.

R DEVELOPMENT CORE TEAM. 2008. R: A language and environment for statistical computing. [Online]. Vienna: R Foundation for Statistical Computing. Available at: http://www.R-project.org. [Accessed: 2009, May 15].

SAS INSTITUTE. 2017. SAS software 9.4. Cary, NC, USA: SAS Institute Inc.

SOYEURT, H., DARDENNE, P., GILLON, A., CROQUET, C., VANDERICK, S., MAYERES, P., BERTOZZI, C. and GENGLER, N. 2006. Variation in fatty acid contents of milk and milk fat within and across breeds. Journal of Dairy Science, 89(12): 4858-4865.

SOYEURT, H., BASTIN, C., COLINET, F., ARNOULD, V., BERRY, D., WALL, E. and MCPARLAND, S. 2012. Mid-infrared prediction of lactoferrin content in bovine milk: Potential indicator of mastitis. Animal, 6(11): 1830-1838.

SOYEURT, H., DEHARENG, F., GENGLER, N., MCPARLAND, S., WALL, E., BERRY, D. P., COFFEY, M. and DARDENNE, P. 2011. Mid-infrared prediction of bovine milk fatty acids across multiple breeds, production systems, and countries. Journal of Dairy Science, 94(4): 1657-1667.

VANLIERDE, A., VANROBAYS, M. L., DEHARENG, F., FROIDMONT, E., SOYEURT, H., MCPARLAND, S., LEWIS, E., DEIGHTON, M. H., GRANDL, F., KREUZER, M., GREDLER, B. DARDENNE, P. and GENGLER, N. 2015. Hot topic: Innovative lactation-stage-dependent prediction of methane emissions from milk mid-infrared spectra. Journal of Dairy Science, 98: 5740-5747.

WALLÉN, S. E., PRESTLØKKEN, E., MEUWISSEN, T. H. E., MCPARLAND, S. and BERRY, D. P. 2016. Milk mid-infrared spectral data as a tool to predict feed intake in lactating Norwegian Red dairy cows. Journal of Dairy Science, 101(7): 6232-6243.

Contact information

Lisa Rienesl: l.rienesl@students.boku.ac.at

Negar Khayatzadeh: negar.khayatzadeh@boku.ac.at

Astrid Köck: koeck@zuchtdata.at

Laura Dale: ldale@lkvbw.de

Andreas Werner: awerner@lkvbw.de

Clément Grelet: c.grelet@cra.wallonie.be

Nicolas Gengler: nicolas.gengler@uliege.be

Franz-Josef Auer: franz.josef.auer@lkv-austria.at

Christa Egger-Danner: egger-danner@zuchtdata.at

Xavier Massart: xmassart@awenet.be

Johann Sölkner: johann.soelkner@boku.ac.at 